\title{
A chegada do inverno ou o que tenho a ver com Kuala Lumpur?
}

\section{Leticia Cantarela Matheus}

\section{Resumo}

0 artigo analisa a dependência das narrativas jornalísticas à marcação do tempo estabelecida pelos próprios jornais, a partir de múltiplos recursos, tais como a datação, as efemérides, as sínteses históricas, além do olhar para a cotidianidade. Para isso, desenvolve uma tipologia de usos jornalísticos do tempo segundo a qual existem funções pragmáticas, historiográficas e cosmológicas, de medição e mediação do tempo.

Foram analisadas centenas de exemplares de três periódicos com mais de cem anos no Rio de Janeiro, compondo um panorama de 180 anos. A pesquisa indica que os jornais servem para oferecer um conformo simbólico de domínio do tempo e que dessa função depende também seu status, bem como sua inteligibilidade.

\section{Palavras-chave:}

Comunicação. Mediação. História do jornalismo. Tempo. Narrativa.
Leticia Cantarela Matheus I leticia_matheus@yahoo.com.br Doutora em Comunicação pela Universidade Federal Fluminense (UFF).

\section{Introdução}

"Com a chegada do inverno ontem no Rio, o carioca precisou tirar o agasalho do armário e enfrentou a chuva fina, que continua até sábado segundo meteorologistas." Esse tipo de texto, que redigi inúmeras vezes e que encontramos em periódicos de grande circulação e prestígio, chama a atenção para o espaço privilegiado dedicado a informações climáticas tais como 0 ciclo das estações ou a temperatura em Kuala Lumpur. Surpreende a obstinação na publicação de dados que, a rigor, não se encaixariam nos critérios de noticiabilidade de interesse público e ineditismo. Afinal, poucos leitores devem necessitar saber o clima na Malásia para uma eventual viagem. Além disso, de inédita a chegada do inverno não tem nada, já que o fenômeno se repete todo ano. 0 mais interessante é perceber que as efemérides climáticas estão constantemente no topo dos índices de leitura, quando não são campeãs da atenção do leitor, como constatado nas consultas aos assinantes de um grande jornal do Rio de Janeiro. 
A perplexidade frente a essa dinâmica do consumo jornalístico nos levou perguntar sobre as expectativas que o público nutre acerca do jornalismo. Uma dessas dimensões, pouco explorada, pode ser a de mediação de múltiplas experiências temporais ${ }^{1}$. Para se verificar esse trabalho de marcação dos tempos que tanto caracteriza a natureza do jornalismo, a ponto de seu nome derivar da própria duração - jornada -, foram observadas centenas de exemplares de três periódicos fluminenses nos últimos 180 $\operatorname{anos}^{2}$. A partir daí, estabeleceu-se uma tipologia dos usos jornalísticos do tempo, de modo a compreender suas diferentes apropriações e como o jornalismo cria um sistema próprio de medição/mediação do tempo. 0s tipos por nós desenhados foram: a) uso historiográfico ou midiográfico, cujo uso é mais restrito, porém não menos importante para conferir certo valor simbólico à prática jornalística; b) uso pragmático ou cotidiano, mais perecível; e c) tempo cosmológico (incluindo sua versão mística), também usado para medir a passagem do tempo. 0 último modelo, justamente 0 menos provável e mais surpreendente, explicaria parte do interesse pela chegada do inverno ou pelo clima na capital da Malásia.
A rigor, todos esses recursos medem a passagem do tempo, porém atendendo a expectativas diferentes: 0 historiográfico é entendido como devendo ser usado para tratar o passado; 0 cotidiano é usado para referir um tempo imediato, fugaz; e o cosmológico carrega uma expectativa objetivista, é entendido como sendo "o tempo" em si, não como um conjunto de cálculos matemáticos sobre os movimentos dos astros.

\section{Marcando o tempo}

Uma importante função jornalística é ser mediador do tempo cósmico, como um grande relógio e calendário social, graças principalmente a seu caráter periódico. Essa é uma das temporalidades segundo as quais opera o jornalismo, dentro do complexo conceito de atualidade desenvolvido por Franciscato (2005), que engloba também outras dimensões do tempo: instantaneidade, simultaneidade, novidade e "revelação" (ou enunciação).

As marcas do tempo são especialmente sensíveis nos jornais, localizando o leitor num "lugar" na duração. 0 consumo diário das narrativas jornalísticas fornece um forte parâmetro espaçotemporal. 0 processo de significação dessas narrativas depende da vinculação a uma data,

Evidentemente, essas experiêncis não se limitam ao clima, ao qual nos referimos no primeiro parágrafo. Clima e tempo aqui não estão sendo usados como sinônimos, mas possuem uma relação de continuidade. Tanto as estações do ano quanto a passagem dos dias obedecem ao comportamento dos astros e esse tempo cósmico, atravessado pelo calendário religioso Gregoriano, no Ocidente, é naturalizado como sendo "o" tempo social, entendido, no senso comum, fora da sua dimensão sócio-cultural. É exatamente sobre esses diferentes sistemas de medição/ mediação do tempo pelo jornalismo que trata este artigo. 
criando uma referência jornalística. Apesar de possuir ritmo próprio, sua periodicidade, um jornal vincula aquilo que conta a ritmos referenciais mais amplos. No caso do Ocidente, basicamente 0 calendário Gregoriano. Ao lado do ritmo concreto de produção jornalística, ou seja, do intervalo segundo o qual uma empresa oferta novos produtos, podendo ser uma edição impressa, mas também digital, radiofônica ou televisiva, também a articulação do tempo na narrativa fornece um efeito de correspondência ao calendário. Portanto, a marcação dos tempos se dá por um duplo movimento: de narração (tempo do contar) e na articulação da narrativa (tempo contado).

A correspondência de uma edição a um intervalo de tempo é de fundamental preocupação na feitura de um jornal. Suas narrativas não são soltas para serem apreendidas com liberdade no tempo. A inteligibilidade da narrativa jornalística depende de sua localização na duração. Portanto, o tempo jornalístico do que é contado depende intimamente do seu tempo de contar (RICOEUR, 1994). A notícia não faz sentido isoladamente, sem estar vinculada a uma "territorialidade" espaço-temporal.

Nem sempre a relação estabelecida no jornalismo entre o tempo do contar e o tempo contado foi como hoje. 0 carioca Correio Braziliense (1808-1822), por exemplo, publicado em Londres e enviado ao Brasil por navio, era datado de acordo com o início de sua confecção, não com a publicação. Seu editor (na época se dizia redator), Hipólito da Costa, recolhia informações e escrevia nos 15 primeiros dias do mês e passava os outros 15 fechando 0 jornal e 0 imprimindo. Somente a impressão levava 32 horas. Depois disso, o jornal, que mais parecia um livro, ainda precisava ser embarcado e passava dois meses em trânsito até chegar à costa brasileira. Ou seja, sua datação correspondia a três meses antes da circulação. (MESSAGI JÚNIOR, 2008)

O Fluminense, jornal do município de Niterói (a 14 km do Rio), com 131 anos, publicava em 1898 a coluna "A SEMANA", que, contrariando o nome, não obedecia ao intervalo cronológico de sete dias, contendo informação tanto anterior quanto das semanas seguintes, como uma espécie de pauta tornada pública, a agenda do jornal.

A marcação do tempo foi se tornando função essencial dos jornais, a ponto de lhes ser dada credibilidade para datá-lo. Lembre-se que guerrilheiros fotografavam o sequestrado ao lado de um exemplar do dia, na época da ditadura militar dos anos 1960-1970, para assegurar que estava vivo. A própria assinatura é um contrato que depende de datação para garantir sua vigência. As referências à passagem do tempo vão desde matérias, charges e artigos especiais de final de ano, à data diária no alto de página, e reportagens sobre as efemérides naturais, como a passagem das estações, até o horóscopo, forma de medição mística, já que classifica os indivíduos de acordo com a data do nascimento. 
No início do século XX, a obsessão por fazer coincidirem os tempos era tamanha que Jornal do Brasil publicava uma lista de correspondência da edição aos calendários muçulmano, chinês, copta e positivista. Publicava também, como até hoje se faz, os nascimentos e ocasos do sol e da lua diariamente, entre outros exemplos de fornecimento de sentido de passagem do tempo cósmico: " $1^{\circ}$ de maio: $122^{\circ}$ dia do ano e $1^{\circ}$ dia do $5^{0}$ mez."

Tal obsessão persistiu até o início deste século, por exemplo, no Jornal do Commercio, que relaciona a edição às datas correspondentes com precisão: "3, 4 e 5 de agosto de 2007, fim de semana" ou " 14,15 e 16 de junho de 1997 - domingo, $2^{\mathrm{a}}$ e $3^{\mathrm{a}}$ feira." Em seu primeiro ano (1827), vinculava seu próprio tempo ao tempo político do Império, destacando no alto da página: "Sexto anno da Independência". 0 Jornal do Brasil também publicava: "Edição da manhã, sabbado, 9 de fevereiro de 1901 - anno 40". Ou seja, importava capitalizar, jornalisticamente, não apenas a passagem do tempo cósmico, mas a própria contagem do tempo feita pelo jornal.

Vários sistemas de marcação do tempo são disputados nas páginas de um jornal como tempos de significação social: desde os místicos até os do mundo do trabalho (por hora nos Estados Unidos, por mês no Brasil, os ciclos da indústria têxtil em função dos ciclos da moda), passando pela fantasia. Desde os folhetins, que obedecem a periodicidades diferentes das edições (instaurando, além disso, outros tempos ficcionais), os ritmos da natureza, com as previsões meteorológicas (consequência, afinal, dos ciclos atmosféricos), as tábuas de marés, 0 início das estações, até os tempos místicos zodiacal e religioso.

Mesmo antes dos modernos cálculos meteorológicos, o Jornal do Commercio mantinha, na segunda metade do século XIX, nota de primeira página com a descrição do clima no dia anterior, não como previsão: "Choveu às 7h". No dia 5 de julho de 1898 fez 20 graus no Fonseca, em Niterói: "Temperatura no Fonseca (dentro de casa): Min. 20 graus. Máx. 21 graus." (O Fluminense, 05/06/1898, p. 1) Ou seja, mesmo antes da capacidade de previsão, era importante registrar a temperatura do dia anterior para que 0 leitor tentasse deduzir qual seria a do dia corrente ou simplesmente por curiosidade, para ter argumentos nas conversas sobre o quanto sofrera com o calor ou com o frio.

Foram encontrados inúmeros exemplos de uso cosmológico e cosmogônico do tempo (o que seria sua versão mística). Separou-se a amostragem em quatro tipos: os marcadores da vida biológica (aniversários, comemorações, obituários, bodas); os marcadores da vida mística (calendários religiosos, zodiacais); os ciclos cósmicos (estações climáticas, calendário gregoriano); e, por fim, 0 tempo histórico (efemérides e comemorações).

Como ressalva, é preciso dizer que os usos do tempo não produzem significações 
exclusivamente cosmológicas, sendo esta divisão apenas recurso metodológico. Por exemplo, o mesmo tempo histórico que serve para dar sentido às ações sociais, com um sentido de apreensão de passado (historiografia), funciona também como tempo físico naturalizado. $\mathrm{Ou}$ seja, o tempo social é enquadrado no calendário Gregoriano que, por sua vez, tenta reproduzir, em parte, a lógica dos ciclos astrofísicos. Por isso, alguns dos "tempos" aqui destacados podem figurar em mais de uma categoria.

\section{Cosmologias e cosmogonias}

Apareceram inúmeros exemplos de usos cosmológicos e cosmogônicos do tempo nesses jornais. Separou-se a amostragem em cinco formas de sistematização do tempo de acordo com: marcadores da vida biológica (aniversários, comemorações, obituários, bodas); marcadores da vida mística (calendários religiosos, zodiacais); marcadores ficcionais (por exemplo, o folhetim); e marcadores dos ciclos cósmicos (estações climáticas, calendário gregoriano). Observa-se que esses marcadores não sensibilizam para significações exclusivas, tendo sido essa divisão apenas metodológica. Por exemplo, é evidente que o tempo histórico, que serve para dar sentido às ações coletivas do homem no tempo, funciona também como tempo físico naturalizado. Comecemos, então, pelo tempo biológico.

No Fluminense, a passagem da vida biológica tem lugar especial no caderno "Pingo de Gente" (que oscila entre duas fases como tabloide separado e coluna no "Segundo Caderno"), dedicado ao público infantil e publicado aos domingos. Nele, são publicadas, na "Galeria de Sócios", fotografias de crianças que recebem carteirinhas do jornal e ganham 0 direito de enviar desenhos a ser publicados na coluna "Arte dos artistas". Além de fidelizar público futuro, O Fluminense acabava assim atendendo à vaidade dos pais de ver a imagem de seus filhos estampada no jornal, além produzir um efeito de registro do tempo, pois o crescimento infantil e o desenvolvimento de suas capacidades motoras e intelectuais ao desenhar foram sendo fixados em um instante da duração. Olhar essas páginas antigas em sequência é como folhear um grande álbum da cidade, com fotografias dos moradores segundo temporalidades totalmente descoladas do presente "agora mesmo" 2010. São crianças que ou são velhos ou já morreram. Três ou mais gerações fixadas numa mesma faixa etária. Avós, pais e filhos coexistindo em imagem criança.

Não apenas a vida, visualmente materializada no crescimento das crianças, mas também a morte, evidentemente, tem lugar especial nos jornais. Desde as mortes imprevistas, contadas nos crimes e tragédias, até as mortes dos anônimos nos avisos fúnebres, e sobretudo dos ricos e famosos, destacadas nos obituários, mantidos com perseverança pelos periódicos, assim como as notas sociais, que destacam casamentos, aniversários, bodas: "Parabéns. Hoje faz annos a menina Maria Augusta, dilecta filha do sr. Bernardino da Silva Carvalho" foi a nota 
publicado no Jornal do Commercio em 1898.

(Jornal do Commercio, 01 set. 1898, p. 1)

Tanto ele quanto o Jornal do Brasil mantiveram espaços dedicados à religiosidade, 0 que seria a contribuição cosmogônica do jornalismo.

Ambos traziam colunas que tinham por função manter o calendário cristão como referencial de ordenamento do tempo: "Notas Religiosas" no Jornal do Brasil e "VIDA CATHOLICA" no Jornal do Commercio. Embora as colunas articulassem questões espirituais especificamente (Quanto pesa a alma? Entre 11 e 45 gramas - Jornal do Commercio, 21/07/1907, p. 2; Predestinação, elevação sobrenatural do gênero humano), eram majoritariamente dedicadas à hagiografia. Como uma espécie de efeméride católica, contavam a história do santo do dia, além da agenda de missas e reproduções das homilias. No Jornal do Brasil, essas "Notas Religiosas" foram publicadas até pelo menos os anos 1950. Já O Fluminense mantinha uma coluna espírita e dava espaço a outras denominações religiosas:

Mãe Luisinha [responsável pela ala das baianas desde 1959] fez oferendas, jogou búzios e confia num grande desfile da [Acadêmicos do] Cubango (0 Fluminense, domingo e segunda, 7 e 8 fev. 1988, p. 1). São Sebastião para os católicos e 'Oxossi' para os umbandistas, São Sebastião foi festejado ontem nesta Capital e na Guanabara, de onde é padroeiro (0 Fluminense, quarta-feira, 21 jan. 1971, p. 1)

Quem domina 0 tempo domina as pessoas. "A divisão do tempo é uma das concepções mais ousadas e mais úteis do espírito humano", disse o relator do projeto de criação do calendário revolucionário francês, sendo os recortes unidades de tempo que funcionam como quadro referencial para as ações (LE GOFF, 1997). 0 principal deles, no mundo Ocidental, é 0 calendário gregoriano. Os jornais estão subordinados a esse ritmo, mas, a definirem sua periodicidade, criam um ritmo particular.

É importante destacar que, mesmo sendo diário, um jornal não reproduz exatamente 0 calendário gregoriano. Segundo a Associação Nacional de Jornais (ANJ), é considerado diário o periódico que circula pelo menos três vezes por semana. Lembre-se que nenhum dos três jornais analisados saiu sempre os sete dias da semana, embora fossem considerados diários. 0 Jornal do Commercio chegou a condensar sábado, domingo e segunda-feira em uma só edição; O Fluminense condensa domingo e segunda; e o Jornal do Brasil "pulava" a segunda-feira nos anos 1930. Portanto, o próprio status "diário" é um efeito narrativo sintetizado nas edições.

Diante da importância de marcar o tempo e se apropriar do calendário gregoriano, as empresas jornalísticas imprimiam e/ ou revendiam folhinhas. O Fluminense anunciava em 1928 (03 jan., p. 1): "Recebemos lindas folhinhas para 0 corrente anno, das importantes casas comerciaes seguintes: Da Typographia e Papelaria Jeronimo Silva; Da Alfaiataria Regina [...]; Da Casa Floresta [...]." O Jornal do Commercio vendia as famosas Laemmert no século XIX e, em 1948, 
imprimia sua própria, encartada como brinde:

"Como acontece todos os anos, com a edição de hoje será distribuída a folhinha do JORNAL DO COMMERCIO, sem que por isso haja alteração no preço habitual da folha." (Jornal do Commercio, $1^{\circ}$ jan. 1948, p. 1) Ou seja, durante muito tempo a obtenção das folhinhas podia estar associada ao título de preferência do leitor.

Além de objeto físico, os calendários são sistemas de significação dos quais os jornais se apropriam para construir sua inteligibilidade. Assim, eles próprios se tornam objeto e sistema cultural de temporalização, objetivando o sistema calendário. Constituem-se em organizadores dos múltiplos quadros temporais justamente por se apropriarem de tantos diferentes e, sobretudo, por mediarem os tempos cotidianos e históricos.

Gradativamente foi se atribuindo aos jornais essa função-calendário de organização do tempo social. Enquanto as folhinhas figuram nas paredes das cozinhas, nas portas de geladeira, nas pesas dos escritórios e na versão digital em aparelhos celulares e no computador, funcionando como calendário privado (assim como os almanaques), os jornais desempenham função-calendário público. Mas não só isso, a mídia em geral funciona efetivamente como relógio, quando se organizam os dias não só em função do trabalho, mas também da programação das emissoras de rádio e TV (BARBOSA, 2007).
Quem consegue impor seu sistema de temporalização tem vantagem em relação aos demais. Le Goff (1997) mostra como 0 catolicismo se apropriou com incrível habilidade dos calendários pagãos e descreve a invenção de instrumentos de medição do tempo, como, por exemplo, o século, adotado pelos historiadores no século XVIII como forma historiográfica de contar o tempo. Da mesma forma, a periodicidade de um jornal constitui $o$ instrumento de dominação do tempo pelo jornalista e o jornal como instrumento de dominação do tempo pela sociedade.

É verdade que a crescente complexificação das sociedades contemporâneas, com a experiência de múltiplos ritmos, extrapola a resposta que um jornal impresso pode dar, já que seu ritmo é governado pela impressão. Por outro lado, sua leitura sempre recoloca a comunicação em novo fluxo, dá partida a novos processos, e sua periodicidade marca fortemente os ritmos sociais. Não somente pela organização do cotidiano, tendo como referência esses tempos, mas também pelas interferências na administração pública, como, por exemplo, pela lógica da "prestação de contas" (MAIA, 2004), segundo a qual as autoridades de Estado pautam suas ações pelo ritmo da reposta que precisam dar à mídia em vez, muitas vezes, de focar em iniciativas de longo prazo.

\section{A metáfora da efeméride astrofísica}

Desde as famosas Ephemérides Brazileiras do Barão do Rio Branco, publicadas pelo Jornal 
do Brasil a partir de seu segundo número, em 1891, esse tipo de narração se tornou uma febre. A efeméride é um recurso curioso, pois torna o passado vinculado à atualidade. Assim, algo circunstancial recebe uma aura de ineditismo, graças à marcação do tempo, podendo assim ser convertido em notícia, como no exemplo: "50 anos de Hollywood tropical. A Atlântida reúne um acerco de 62 filmes com o melhor da chanchada" (Jornal do Brasil, Caderno B, 21 jul. 1991, p. 8). Simplesmente se queria falar da produtora, mas, na falta de adequação de novidade, usou-se o tempo cósmico como "gancho", subordinado-o ao jornalístico.

Embora funcionassem como marcação de um tempo cíclico, as efemérides podiam ser também oportunidade de apresentar interpretações sobre o passado, usadas tanto isoladamente quanto vinculadas a análises mais amplas.

\section{EPHEMERIDES BRAZILEIRAS}

2 de novembro de 1615 - N'este dia completou-se a capitulação do forte de São Luiz do Maranhão, ficando De La Ravardiére entendido de que deveria entregá-lo "com toda a artilharia... (veja 31 de outubro a 2 de novembro) (Jornal do Brasil, 27 nov. 1891, p. 2)

Na sequência há outras notas referentes a 4 e 6 de novembro, ou seja, as datas das edições atuais e antigas não coincidiam sempre, o que não diminuía a inteligibilidade de sua forma de organização do tempo e da história. Até pelo menos 1945 as Ephemérides do Barão do Rio Branco, que já havia morrido em 1912, ainda eram debatidas e corrigidas no Jornal do Brasil de acordo com os membros do Instituto Histórico e Geográfico Brasileiro e ainda são utilizadas como referência, como muitas vezes ocorreu nesta pesquisa mesma.

0 recurso da efeméride para lembrar o passado pode ser interpretado como uma apropriação, pelo jornal, do tempo cósmico, dando-lhe sentido de história, já que originalmente uma efeméride é um cálculo astrofísico. Ao adotar esse conceito que serve à marcação da mecânica dos astros e aproximá-lo do tempo do jornalismo, o leitor tem a garantia de que é tão certo o jornal estar nas bancas na manhã seguinte quanto a própria certeza da manhã seguinte. São formas de mediação do tempo: um físico, outro jornalístico.

Apresentar uma coluna exclusiva com efemérides confere a elas caráter mais autônomo em relação às demais narrativas, como nem sempre funcionou, a exemplo do editorial sobre a queda da Bastilha, na celebração do 14 de julho, que O Fluminense aproveitou para apresentar sua análise "historiográfica" da Revolução Francesa (14 jun. 1898). As efemérides serviam também como pretexto para discorrer sobre algum assunto, como neste caso, inclusive sob uma perspectiva historiográfica ou memorialística.

De todas as efemérides, as principais são as colunas ao estilo "Memória". São aquelas que listam acontecimentos noticiados pelos jornais há 50, cem e 150 anos e que transportam 0 
leitor para outro universo, narrando o passado enquanto história.

\section{MEMÓRIA}

0 Jornal do Commercio publicava na edição de 2 de agosto:

HÁ 150 ANOS

Anteontem, por volta das $19 \mathrm{~h} 30 \mathrm{~m}$, foi preso por dois pedestres 0 capoeirista Raphael, que estava armado com uma navalha. Ele foi preso na Rua São Joaquim, mas quando os três chegaram ao Largo da Carioca os pedestres foram atacados por mais seis pretos que dominam esta mesma luta. Eles conseguiram, na luta, soltar o dito Raphael e fugiram em seguida. Neste conflito um dos pedestres ficou ferido. Que haja providência contra esses desordeiros. (Jornal do Commercio, 3,4 e 5 ago. 2007, p. A-18)

A efeméride foi selecionada por José Pinheiro Júnior; fato raro, nesses quase dois séculos, 0 de identificar o responsável pela coluna. 0 texto reproduz a maneira antiga de escrever, o que nem sempre ocorria. Muitas vezes, as histórias eram reescritas ao modo contemporâneo, para facilitar a compreensão. Por outro lado, perdiam parte do sabor do tempo.

0 texto remete a outro mundo. Enquanto narrativa, abre uma fenda para o passado, como um túnel do tempo. 0 leitor é capaz de imaginar tanto o universo do capoeirista com nome de pintor italiano, os conflitos nas ruas do Rio, quanto o universo da produção jornalística, que fez com que se selecionasse esse episódio para ser notícia em 1857 e efeméride em 2007. Assim, um mesmo acontecimento muda de estatuto comunicativo em 150 anos. Ele é despojado de sua densidade ao ser articulado como passado. Por outro lado, enquanto referencial, a história nunca é a mesma, pois a situação comunicacional já é outra. Embora tenha acontecido efetivamente, 0 acontecimento só poderá ser experimentado 150 anos mais tarde enquanto narração. Só a narrativa poderá abrir-lhe a porta e fazê-lo durar. Afinal, foi sua narração pelo Jornal do Commercio que possibilitou que esta autora e talvez o senhor (a), leitor (a), soubéssemos dele 154 anos depois.

Ao mesmo tempo em que a narrativa condensa várias ações que duraram intervalos diferenciados ( 0 caminhar até 0 Largo da Carioca, a prisão, a briga, a fuga), criando uma concordância, ela também se distende no tempo, já que a comunicação efetivamente durou. $\mathrm{Ou}$ seja, ela foi acionada na primeira publicação, na primeira leitura, na apropriação de Pinheiro Júnior, na sua transcrição aqui, e agora na leitura que neste momento o (a) senhor (a) opera. Várias dimensões temporais são produzidas e experimentadas ao narrar (RICOEUR, 1994).

\section{Usando a história}

A presença dessas múltiplas dimensões do narrar estão não apenas nas efemérides, mas também nas contextualizações dos acontecimentos e nas memórias compartilhadas pelos leitores que fazem com que o jornal seja inteligível. Representar o passado de certa forma chancela aos jornais a defensa da memória do país e o registro do tempo, pressupondo com isso certa concepção de história. Aos jornalistas, 
a semelhança com o trabalho do historiador também conferia poder especial, aproximandoos idealmente de um intelectual paradigmático, intérprete privilegiado do passado.

Em 27 de abril de 1888, O Fluminense anunciava vender por $1 \$ 000$ o exemplar especial "0 Abolicionismo Perante a História ou 0 Diálogo das Três Províncias" (p. 4), que apresentaria uma síntese do problema. Durante o mês que antecedeu a abolição, o jornal publicou diariamente editoriais refletindo sobre as novas perspectivas econômicas.

Embora a abolição fosse um problema do presente, o jornal teve pressa não só em interpretar os acontecimentos no seu desenrolar como em produzir um material mais perene. A oportunidade de capitalizar financeira e simbolicamente aquele momento e de se tornar seu intérprete privilegiado fica evidente na reprodução integral na primeira página do dia 16 de maio de 1888 da Lei Áurea.

Cem anos mais tarde, 0 diário ainda explorava 0 fato de ter reproduzido a Lei, referendando a iniciativa dos jornalistas do passado na edição centenária (1978) e na de 130 anos (2008). Ou seja, a urgência em enxertar sentido histórico ao presente, da qual Nora (1976) acusava a mídia nos anos 1970, talvez seja mais antiga ou constitua uma operação característica e definidora do jornalismo.

Por exemplo, o Jornal do Brasil não havia completado um ano de circulação e já promovia sua coleção como registro relevante que deveria ser comprado e preservado. Anunciou a venda de uma compilação de seus textos:

\section{BIBLIOTECA DO JORNAL DO BRASIL}

Brevemente começaremos a editar em elegante volume in-8, nitidamente impresso em excellente papel e ao preço uniforme de $3 \$$ o volume (2\$ para nossos assinantes), o melhor de nossa collaboração estrangeira e nacional, sob o titulo geral de 'Biblioteca do Jornal do Brasil' 0 primeiro volume está no prelo e terá por titulo Dom Pedro II e conterá todos os artigos publicados em nossa folha sobre 0 fallecido ex-Imperador. A este seguir-se-hão: Chronicas litterarias por Theophilo Braga, Dia a Dia, chronica alegre dos acontecimentos diários, Ephemerides brazileiras pelo Barão do Rio Branco, A Amazônia por José Veríssimo e successivamente os magnificos trabalhos expressamente para este jornal escriptos por Schimper (Jornal do Brasil, 30/12/1891, p. 1, grifo nosso).

Desde seu primeiro ano, o Jornal do Brasil trabalhava para que se atribuísse valor de perenidade ao produto, acrescentando valor simbólico extra ao título. Fica evidente no trecho acima uma intenção registradora do tempo que se confundia com a ideia de história. Porém, ao lado de registros históricos e literários, supostamente não condicionados por um instante determinado de leitura, o jornal ofertava compilações de seu material mais perecível e mais dependente do cotidiano: as crônicas alegres dos acontecimentos diários. Elas eram apresentadas em uma coluna cujo nome já materializava a temporalidade do cotidiano: "Dia-a-dia". Tão explícita como no título da coluna, a própria cotidianidade é 0 terceiro tipo de tempo usado nos jornais. 


\section{0 tempo da cotidianidade}

A vida diária, na sua dimensão mais intensa, 0 tempo pragmático da ação, explode nas páginas de $O$ Fluminense e no Jornal do Brasil desde 0 século XIX. Ela dá o ritmo das narrativas e marca sua perecibilidade. Licitações de serviços públicos, assassinatos, navalhadas, notícias marítimas, ataques piratas a cargueiros na costa, leilões, casamentos, aniversários, obituários, notas sociais, câmbio, classificados, "raptos e defloramentos", campanhas assistencialistas, medidas administrativas para garantir a qualidade da carne são exemplos desse conteúdo dos dois jornais entre as décadas de 1890 e 1920.

Fica patente a força do noticiário, ainda que sob os parâmetros da época. Eram preocupações as mais imediatas e pragmáticas possíveis: os classificados - alguém precisa vender alguma coisa e alguém precisa comprar -, a escala dos comissários de polícia de plantão nas delegacias, o resultado do turfe e do jogo do bicho - se alguém jogou, é preciso aplacar a expectativa mais imediata de saber se ganhou -, a programação dos cinemas - também uma forma de planejamento do uso do tempo, entre tantos outros exemplos.

0 anúncio da ampliação da Estrada de Ferro Central do Brasil, que ganharia uma quarta linha, pelo Jornal do Brasil, por exemplo, é, em 1897, motivo de capitalização simbólica, estando o pioneirismo, o ineditismo e a exclusividade já presentes, derivados de uma pragmática: "O público teve hontem conhecimento, por intermédio somente do Jornal do Brasil, de que esta importantíssima repartição vae ser dotada de um melhoramento de alta importância."

(Jornal do Brasil, 04 abr. 1897, p. 1)

Aquilo a que se está chamando de cotidiano é um conceito complexo que, embora muitas vezes seja erroneamente tratado como "rotina", inclui rotina, mas incorpora também a reflexão acerca da realidade e sua efetiva transformação. Optouse pela definição de Heller (1992): "cotidiano é a vida do homem inteiro".

É no cotidiano que se faz a história, em que 0 homem experimenta sua integralidade, tanto com seus hábitos mais firmemente estabelecidos quanto com as surpresas que os outros e que suas ações produzem no curso de sua própria vida e na dos demais. Ou seja, é no cotidiano, incluindo todas as dimensões da vida social, como a comunicação, que as rupturas e continuidades são tencionadas na experiência imediata $\mathrm{e}$ distendidas na duração. Usando Ricoeur (1994), é onde condensamos e/ou expandimos o tecido temporal da experiência. É no cotidiano que fazemos história ao agir, ao sofrer a ação dos outros, ao nos omitirmos ou simplesmente quando não tomamos conhecimento de um sem número de realidades alheias. Ou seja, a integralidade do processo histórico não poderia se dar em outro lugar que não no cotidiano.

A dimensão do fazer histórico é explicada de maneira simples por Heller (1993) ao afirmar que todos somos historiadores, teóricos e 
filósofos da história na medida em que contamos histórias, analisamos as histórias que vivemos, vemos e ouvimos e interpretamos essas histórias, apropriando-as a nossa maneira. Portanto, o processo histórico, como ato comunicacional de significar, não poderia ficar mais evidente:

Dar sentido a alguma coisa significa mover os fenômenos, as experiências e similares, para dentro de nosso mundo; significa transformar 0 desconhecido em conhecido, 0 inexplicável em explicável, bem como reforçar ou alterar 0 mundo por ações significativas de diferentes proveniências. (HELLER, 1993, p. 85)

Fica patente que é no cotidiano que se processa a comunicação, como ato de dar sentido que se dá na duração. Nesse caso, interessam os atos interligados e coletivos de criar sentidos socialmente, ou seja, interessa a comunicação enquanto trabalho de natureza social. É preciso buscar outros status que esse modo de interação social foi adquirindo ao longo do tempo para perceber os resquícios, as sobreposições, as transformações, as substituições, as radicais rupturas entre diferentes modos de fazê-lo e seus diferentes usos sociais.

A notícia, uma das principais marcas narrativas do jornalismo atualmente, aparece no passado como efeito da percepção de novidade dentro do fluxo comunicacional cotidiano. A notícia, como experiência particular do tempo, foi sendo reforçada e separada de análises "de fundo", que davam um panorama mais profundo temporalmente. Assim, o leitor foi se satisfazendo com significados mais imediatos, enquanto 0 valor de perenidade do jornal foi sendo diluído. 0 passado foi se tornando mais raso, com pouca profundidade temporal.

A presença do cotidiano, como dimensão pragmática do presente, ocupa a maior parte dos três jornais em estudo. Ela está na urgência da morte, em crimes e tragédias, no fascínio pela tecnologia, como antecipação de futuro, nas atividades comercial e industrial, como ritmo do trabalho e da oportunidade capitalista, na programação cultural e seu modo de ordenamento do tempo, nos dramas da vida urbana, no conflito de geração explicitado nas reportagens de comportamento, e também nos anúncios publicitários, que fornecem intenso senso de presente. Todos esses assuntos davam um sentido de urgência de ação, que era experimentada no consumo dos periódicos.

\section{Considerações finais}

0 estabelecimento dessa tipologia dos usos do tempo permitiu compreender que a leitura sobre a chegada do inverno funciona realmente como um importante vínculo do leitor com seu jornal. Observou-se que o jornalismo funciona como um moderno instrumento de medição que fornece a sensação de domínio do tempo, não mais por rituais religiosos, mas por objetivações midiáticas. Assim, fica fácil entender porque, além das histórias do passado e principalmente das histórias do presente, o tempo astrofísico possui valor fundamental para a narratividade dos jornais. 
Anunciar que o inverno chegou é medir a passagem dos meses, do ano, enfim, do tempocalendário, e publicar o clima da Malásia é promover uma consciência de simultaneidade de tempo e espaço, enfim, da própria historicidade, como dizem Franciscato (2005) e Anderson (2008). 0 clima de Kuala Lumpur está ali não porque a multidão de turistas consulte 0 jornal para saber que roupa levar na viagem, mas para ter a sensação de domínio sobre a territorialidade do mundo e sua dimensão temporal.

Não apenas a marcação do tempo histórico é importante para um jornal, mas também a marcação do tempo-calendário. A apropriação dessa temporalidade pelo jornalismo permite ao público localizar e validar não apenas as histórias ouvidas no cotidiano, mas principalmente as histórias contadas pelos próprios jornais, de modo a manterem maior ou menor perecibilidade. Graças a essa temporalidade, o público constrói parte dos vínculos entre as narrativas jornalísticas e sua realidade concreta. Essa função de datação e de medição do tempo garante parte de seu status comunicacional e faz com que o jornalismo não seja confundido com outras formas de representação que também ocupam lugar central no cotidiano. A datação, a passagem do tempo, as viradas das estações etc. são seu ancoradouro temporal e ancoradouro das notícias, aquilo que permite a verossimilhança, de modo a exercer autoridade para representar 0 tempo concreto do viver.

\section{Referências}

ANDERSON, Benedict. Comunidades imaginadas. SP: Companhia das Letras, 2008.

BARBOSA, Marialva. Percursos do olhar: comunicação, narrativa e memória. Niterói: EdUFF, 2007.

FRANCISCATO, Carlos Eduardo. A fabricação do presente: como o jornalismo reformulou a experiência do tempo nas sociedades ocidentais. São Cristóvão: UFS; Aracaju: Fundação Oviêdo Teixeira, 2005.

HELLER, Agnes. 0 cotidiano e a história. 4 ed. São Paulo: Paz e Terra, 1992.

HELLER, Agnes. Uma teoria da história. Rio de Janeiro: Civilização Brasileira, 1993.

LE GOFF, Jacques. Calendário. In: Enciclopédia

Einaudi. Portugal: Imprensa Nacional - Casa da Moeda, 1997, p. 260-292.

MAIA, Rousiley. Visibilidade e accountability: 0 evento do ônibus 174. Comunicação e Política, Brasília, pp. 1-26 (Não consigo descobrir vol e n.), 2004. Disponível em: <http:/www.unb.br/fac/comunicacaoepolitica/ rousiley2004.pdf>. Acesso em: 15 fev. 2011.

MESSAGI JÚNIOR, Mário. 2008. 0 texto jornalístico no centro de uma revisão da história da imprensa no Brasil. Tese (Doutorado em Comunicação)Universidade do Vale dos Sinos, São Leopoldo, 2008.

NORA, Pierre. 0 retorno do fato. In: LE GOFF, JACQUES ; (orgs.). História: novos problemas. Rio de Janeiro: Francisco Alves, 1976. p. 179-193.

RICOEUR, Paul. Tempo e narrativa: tomo I. Campinas: Papirus, 1994. 


\section{The beginning of the winter or what} do I have to do with Kuala Lumpur?

\section{Abstract:}

The paper analyzes the dependence of journalistic narratives on time landmarks, established by the newspapers themselves, from multiple resources, such as dating, the ephemeris, history synthesis, as well as looking at everyday life. This article also develops a typology of different journalistic uses of time, according to which functions are pragmatic, historiographical and cosmological, of measuring and mediation time. The research analyzes hundreds of copies of three newspapers with more than one hundred years in Rio de Janeiro, composing a panorama of 180 years. It indicates that newspapers are made to provide symbolic comfort, as to pretend we dominate time. Its status and intelligibility also depend on this social function.

\section{Keywords:}

Communication. Mediation. History of journalism. Time. Narrative.

\section{El comienzo del invierno 0 ¿qué tengo que ver con Kuala Lumpur?}

\section{Resumen:}

El artículo analiza la dependencia de las narrativas periodísticas de la marcación del tiempo, establecida por los propios periódicos, desde múltiples recursos, tales como las fechas, las efemérides, las síntesis de historia, así como desde la mirada para la vida cotidiana. Para eso, se desarrolla una tipología de los diferentes usos periodísticos del tiempo, según la cual hay las funciones pragmática, historiográfica y cosmológica, de la medición y de mediación del tiempo. Se analizaron cientos de ejemplares de tres periódicos con más de cien años en Río de Janeiro, componiendo un panorama de 180 años. La investigación indica que los periódicos sirven para ofrecer comodidad simbólica de dominio del tiempo y que de esta función dependen también su status y su inteligibilidad.

\section{Palabras clave:}

Comunicación. Mediación. Historia del periodismo. Tiempo. Narrativa. 


\section{Expediente}

A revista E-Compós é a publicação científica em formato eletrônico da Associação Nacional dos Programas de Pós-Graduação em Comunicação (Compós). Lançada em 2004, tem como principal finalidade difundir a produção acadêmica de pesquisadores da área de Comunicação, inseridos em instituições do Brasil e do exterior.
E-COMPÓS I www.e-compos.org.br I E-ISSN 1808-2599

Revista da Associação Nacional dos Programas de Pós-Graduação em Comunicação. Brasília, v.13, n.3, set./dez. 2010.

A identificação das edições, a partir de 2008 passa a ser volume anual com três números.

\section{CONSELHO EDITORIAL}

Afonso Albuquerque

Universidade Federal Fluminense, Brasil

Alberto Carlos Augusto Klein

Universidade Estadual de Londrina, Brasi

Alex Fernando Teixeira Primo

Universidade Federal do Rio Grande do Sul, Brasil

Alfredo Vizeu

Universidade Federal de Pernambuco, Brasi

Ana Carolina Damboriarena Escosteguy

Pontifícia Universidade Católica do Rio Grande do Sul, Brasil

Ana Silvia Lopes Davi Médola

Universidade Estadual Paulista, Brasil

André Luiz Martins Lemos

Universidade Federal da Bahia, Brasil

Ângela Freire Prysthon

Universidade Federal de Pernambuco, Brasil

Antônio Fausto Neto

Universidade do Vale do Rio dos Sinos, Brasil

Antonio Carlos Hohlfeldt

Pontifícia Universidade Católica do Rio Grande do Sul, Brasil

Arlindo Ribeiro Machado

Universidade de São Paulo, Brasil

César Geraldo Guimarães

Universidade Federal de Minas Gerais, Brasil

Cristiane Freitas Gutfreind

Pontifícia Universidade Católica do Rio Grande do Sul, Brasil

Denilson Lopes

Universidade Federal do Rio de Janeiro, Brasil

Eduardo Peñuela Cañizal

Universidade Paulista, Brasil

Erick Felinto de Oliveira

Universidade do Estado do Rio de Janeiro, Brasil

Francisco Menezes Martins

Universidade Tuiuti do Paraná, Brasil

Gelson Santana

Universidade Anhembi/Morumbi, Brasil

Goiamérico Felício

Universidade Federal de Goiás, Brasil

Hector Ospina

Universidad de Manizales, Colômbia

Herom Vargas

Universidade Municipal de São Caetano do Sul, Brasil

leda Tucherman

Universidade Federal do Rio de Janeiro, Brasil

Itania Maria Mota Gomes

Universidade Federal da Bahia, Brasil

Janice Caiafa

Universidade Federal do Rio de Janeiro, Brasil

Jeder Silveira Janotti Junior

Universidade Federal da Bahia, Brasil
João Freire Filho

Universidade Federal do Rio de Janeiro, Brasil

John DH Downing

University of Texas at Austin, Estados Unidos

José Luiz Aidar Prado

Pontifícia Universidade Católica de São Paulo, Brasil

José Luiz Warren Jardim Gomes Braga

Universidade do Vale do Rio dos Sinos, Brasi

Juremir Machado da Silva

Pontifícia Universidade Católica do Rio Grande do Sul, Brasil

Lorraine Leu

University of Bristol, Grã-Bretanha

Luiz Claudio Martino

Universidade de Brasília, Brasil

Maria Immacolata Vassallo de Lopes

Universidade de São Paulo, Brasil

Maria Lucia Santaella

Pontifícia Universidade Católica de São Paulo, Brasil

Mauro Pereira Porto

Tulane University, Estados Unidos

Muniz Sodre de Araujo Cabral

Universidade Federal do Rio de Janeiro, Brasil

Nilda Aparecida Jacks

Universidade Federal do Rio Grande do Sul, Brasil

Paulo Roberto Gibaldi Vaz

Universidade Federal do Rio de Janeiro, Brasil

Renato Cordeiro Gomes

Pontifícia Universidade Católica do Rio de Janeiro, Brasil

Ronaldo George Helal

Universidade do Estado do Rio de Janeiro, Brasil

Rosana de Lima Soares

Universidade de São Paulo, Brasil

Rossana Reguillo

Instituto Tecnológico y de Estudios Superiores do Occidente, México

Rousiley Celi Moreira Maia

Universidade Federal de Minas Gerais, Brasil

Samuel Paiva

Universidade Federal de São Carlos, Brasil

Sebastião Albano

Universidade Federal do Rio Grande do Norte, Brasil

Sebastião Carlos de Morais Squirra

Universidade Metodista de São Paulo, Brasil

Simone Maria Andrade Pereira de Sá

Universidade Federal Fluminense, Brasi

Suzete Venturelli

Universidade de Brasília, Brasil

Valério Cruz Brittos

Universidade do Vale do Rio dos Sinos, Brasil

Veneza Mayora Ronsini

Universidade Federal de Santa Maria, Brasil

Vera Regina Veiga França

Universidade Federal de Minas Gerais, Brasil

COMISSÃO EDITORIAL

Felipe da Costa Trotta I Universidade Federal de Pernambuco, Brasi Rose Melo Rocha I Escola Superior de Propaganda e Marketing, Brasil Adriana Braga I Pontifícia Universidade Católica do Rio de Janeiro, Brasil CONSULTORES AD HOC

Virginia Pradelina da Silveira Fonseca I Universidade Federal do Rio Grande do Norte, Brasil Christa Liselote Berger I Universidade do Vale do Rio dos Sinos, Brasil Márcia Benetti I Universidade Federal do Rio Grande do Sul, Brasil Tattiana Gonçalves Teixeira I Universidade Federal de Santa Catarina, Brasil

Gislene da Silva I Universidade Federal de Santa Catarina, Brasil José Afonso Junior I Universidade Federal de Pernambuco, Brasil EDIÇÃO DE TEXTO E RESUMOS I Everton Cardoso

TRADUÇÕES PARA O INGLÊS I Sieni Campos, Lisa Earl Castillo e Sabrina Glendhill EDITORAÇ̃̃ ELETRÔNICA I Roka Estúdio
COMPOS I wWw.compos.org.br

Associação Nacional dos Programas de Pós-Graduação em Comunicação

Presidente

Itania Maria Mota Gomes

Universidade Federal da Bahia, Brasil

itania@ufba.br

Vice-presidente

Julio Pinto

Pontifícia Universidade Católica de Minas Gerais, Brasil juliopinto@pucminas.br

Secretária-Geral

Ana Carolina Escosteguy

Pontifícia Universidade Católica do Rio Grande do Sul, Brasil carolad@pucrs.br 